\title{
Towards improving river discharge estimation in ungauged basins: calibration of rainfall-runoff models based on satellite observations of river flow width at basin outlet
}

\author{
W. C. Sun ${ }^{1}$, H. Ishidaira ${ }^{1}$, and S. Bastola ${ }^{2}$ \\ ${ }^{1}$ Interdisciplinary Graduate School of Medicine and Engineering, University of Yamanashi, Kofu, Japan \\ ${ }^{2}$ ICARUS, Department of Geography, National University of Ireland, Maynooth, Ireland
}

Received: 9 June 2010 - Published in Hydrol. Earth Syst. Sci. Discuss.: 25 June 2010

Revised: 13 September 2010 - Accepted: 20 September 2010 - Published: 22 October 2010

\begin{abstract}
Rainfall-runoff models are common tools for river discharge estimation in the field of hydrology. In ungauged basins, the dependence on observed river discharge data for calibration restricts applications of rainfall-runoff models. The strong correlation between quantities of river cross-sectional water surface width obtained from remote sensing and corresponding in situ gauged river discharge has been verified by many researchers. In this study, a calibration scheme of rainfall-runoff models based on satellite observations of river width at basin outlet is illustrated. One distinct advantage is that this calibration is independent of river discharge information. The at-a-station hydraulic geometry is implemented to facilitate shifting the calibration objective from river discharge to river width. The generalized likelihood uncertainty estimation (GLUE) is applied to model calibration and uncertainty analysis. The calibration scheme is demonstrated through a case study for simulating river discharge at Pakse in the Mekong Basin. The effectiveness of the calibration scheme and uncertainties associated with utilization of river width observations from space are examined from model input-state-output behaviour, capability of reproducing river discharge and posterior parameter distribution. The results indicate that the satellite observation of the river width is a competent surrogate of observed discharge for the calibration of rainfall-runoff model at Pakse and the proposed method has the potential for improving reliability of river discharge estimation in basins without any discharge gauging.
\end{abstract}

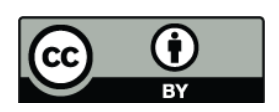

Correspondence to: W. C. Sun (wsun.uy@gmail.com)

\section{Introduction}

As a major link between the continents and the oceans, river discharge is an important component in the global hydrologic and biochemical cycles. Furthermore, it provides essential information for many scientific researches and engineering tasks associated with water resource management and flood hazard prevention. There is a consensus that the current monitoring networks can not detect the complexity of variations in surface water systems adequately (Alsdorf et al., 2007). Nethertheless, these limited in situ networks and access to river discharge information have been reducing in the past decades (Vörösmarty et al., 2001). In recent years, the improvement of river discharge estimation has become a hot topic for researchers in both remote sensing and hydrology.

The remote-sensing approach is promising for increasing the spatial coverage of river discharge estimations globally. With the improvement of sensor technology and successful launches of many satellite platforms from different countries, several surface water hydraulic characteristics of large rivers can be measured or evaluated from remote-sensing data, which include average river width over certain reach length, water surface elevation, water surface slope and channel morphology. In many studies, through empirical relations which work similarly to rating curves for in situ discharge gauging, the information derived from space was used like ground measurements of these hydraulic variables for scaling river discharge at certain cross-sections along a river channel. The empirical rating curves are single-variable relations (e.g., Smith et al., 1995; Zhang et al., 2004; Smith and Pavelsky, 2008; Kouraev et al., 2004; Coe and Birkett, 2004) or multivariate relations (e.g., Smith et al., 1996; Bjerklie et al., 2005; Bjerklie, 2007), in which either river width or water surface elevation is indispensable for scaling

Published by Copernicus Publications on behalf of the European Geosciences Union. 
the cross-sectional area that water flow occupied and the balance between gravity and friction. Water surface elevation is easy for in situ monitoring and intuitional for evaluating the degree of inundation. Therefore, it is more appealing for ground gauging. However, from space, river width observation is more readily available than water stage, as it can be extracted from many kinds of remotely sensed imagery. The current radar altimeters (e.g., TOPEX/Poseidon and Envisat) only provide one dimensional spot water level measurements along orbit track, leaving large areas between orbits unobserved. This problem of sparse spatial coverage could be solved by the future Surface Water Ocean Topography (SWOT) mission (Jet Propulsion Laboratory, 2009). One key obstacle for applications of the empirical relations is the dependence on river discharge data for identifying the rating curve parameters. Until a reliable parameterization scheme could be found, the discharge ratings are generally not applicable to river systems where ground discharge measurements are totally unavailable. The second concern is that uncertainties in satellite observations are larger and more complex than ground measurements. And defining a proper error model is difficult at this moment, as the full evaluation of the errors require comparison between ground and space measurements from large datasets (Bjerklie et al., 2005; Birkett, 1998). Therefore, the impact of measurement error propagation is hard to be evaluated. Another question which needs to be addressed is how to estimate the variation of discharge in the periods between instant measurements, for which the timing is constrained by the satellite repeat cycle.

One specific objective, for the scientific initiative of Predication in Ungauged Basins (PUB) (Sivapalan et al., 2003) launched by the International Association of Hydrological Sciences (IAHS), is reducing uncertainty in river discharge prediction. In the field of hydrology, the rainfall-runoff model is a common tool for extending river discharge both in time and space (e.g., Bastola et al., 2008). Based on the mathematical description of the rainfall-runoff relation for the target basin, it computes the surface runoff corresponding to meteorological forcing data. As a simplified representation of the hydrological cycle, the rainfall-runoff model contains conceptual or physical parameters. Ideally, the models with physical parameters which can be measured or estimated without calibration are preferred. However, applications of such a model are usually difficult. In most cases, fixing parameters through the process of calibration based on observed behaviour for the basin is necessary. The gauged river discharge data at the basin outlet are commonly used as calibration data. For ungauged basins, the main approach for parameter identification is regionalization, which infers the parameters values from the characteristics of the target ungauged basin, based on the statistical relationships between model parameters and basin attributes for a large number of gauged basins (Gupta et al., 2005). As being pointed out by Sivapalan et al. (2003), this kind of extrapolation remains fraught with considerable difficulties and uncertainties.
In this study, the above-mentioned efforts in remote sensing and hydrology are combined together to make a new approach for river discharge estimation in ungauged basins. A new calibration scheme for rainfall-runoff model is proposed. Instead of river discharge data, the calibration is based on river width time series derived from a series of remotesensing images for the basin outlet. One distinct advantage of this approach is that the calibration is independent of in situ gauged discharge data. And unlike regionalization schemes which transfer information from gauged basins to the ungauged basin, only limited remotely sensed information of the ungauged basin is utilized for parameter identification. In recent years, the potential of integration between remotely sensed flood information and hydraulic modelling has been well recognized (Schumann et al., 2009). Analogous to those research works of using inundation area derived from space to constrain the behaviour of hydraulic models (e.g., Montanari et al., 2009), under the proposed method, remotely sensed river widths are utilized to regulate the simulation made by the rainfall-runoff model, which aims at reproducing a long time series of river discharge at the daily time scale. The reason for using river width is that, at this moment, satellite observations of width have wider spatial coverage, compared with water stage. Our method could also make contributions to assess the value of remote-sensing data for solving hydrologic problems, which remains an issue that has not been well understood (Wagner et al., 2009). In the subsequent section, the details about the methodology will be introduced. The calibration scheme is carried out under the generalized likelihood uncertainty estimation (GLUE) framework to quantify the uncertainty in the modelling process. Then a case study at Pakse in the Mekong Basin will be demonstrated, which use river widths derived from Japan Earth Resource Satellite-1 (JERS-1) Synthetic Aperture Radar (SAR) images as calibration data. Finally, based on the results of the case study, the applicability of the methodology will be discussed and some conclusions outlined.

\section{Methodology}

\subsection{Shift the calibration objective of rainfall-runoff model to river width at the basin outlet}

Essentially, a rainfall-runoff model can be considered as a system as follows:

$Q=f(I \mid \eta)$

where $I$ is the model input, such as rainfall, $Q$ is river discharge at basin outlet as output, $\boldsymbol{\eta}$ is the vector of model parameters, $f$ is the group of functions representing the system structure. Model calibration is the process of making the model closely simulate the river discharge at the basin outlet 
by selecting proper values for the parameters. The parameter values being identified are considered as an appropriate representation of the runoff generation process.

The observed river discharge used for regulating model simulation is the time series of the quantity of water that flows through the river channel cross-section at the basin outlet. It can be expressed as the product of cross-sectional water surface width, mean depth and mean velocity. Inversely, from the aspect of river morphology, values of the above-mentioned three components corresponding to certain amount of river discharge reflect the river geomorphology. This is the basis of the at-a-station hydraulic geometry theory (Leopold and Maddock, 1953) which relates the water surface width, depth and velocity, to discharge, at a certain cross-section by the power function, respectively. The power function for depth and flow is commonly used as a rating curve for scaling discharge from in situ gauging of water surface elevation. However, in this study, we focused on developing a rating curve relationship from discharge and river width, because satellite observations have much wider spatial coverage. Based on at-a-station hydraulic geometry, river width can be formulated as follows:

$W=a Q^{b}$

where $Q$ is discharge, $W$ is river width, $a$ and $b$ are two empirical parameters reflecting the hydraulic condition at the cross-section. The exponent $b$ indicates the sensitivity of variation of river width to the change of discharge, which is mainly determined by the shape of the cross-section (Dingman, 2007). The value of $b$ approaches zero as the crosssection shape varies from triangle to rectangle. Traditionally, $a$ and $b$ are derived from regression analysis on a series of values of $Q$ and $W$ measured at the cross-section. The applicability of this function to describe the relation between ground-gauged river discharge and river width observed from space was verified by Smith et al. (1995, 1996, and 2008). In this study, this function is used to shift the observed basin behaviour, which regulates the simulation made by the rainfallrunoff model, from river discharge data to satellite observed river width time series for the basin outlet. More specifically, the simulated discharge is used as input discharge to calculate cross-sectional water surface width based on Eq. (2). Consequently, the river discharge has become a state variable and the river width at the basin outlet has become the output of the integrated model:

$W=g(I \mid \boldsymbol{\theta})$

where $I$ is the same input as in Eq. (1), $\theta$ is the vector of model parameters which include all elements of $\boldsymbol{\eta}, a$ and $b$, $g$ is the system structure which contains the rainfall-runoff functions and Eq. (2). The calibration of this integrated model is accomplished by adjusting each element of $\boldsymbol{\theta}$ simultaneously to find a good fit between river width estimates and satellite measurements, which eliminates the need of river

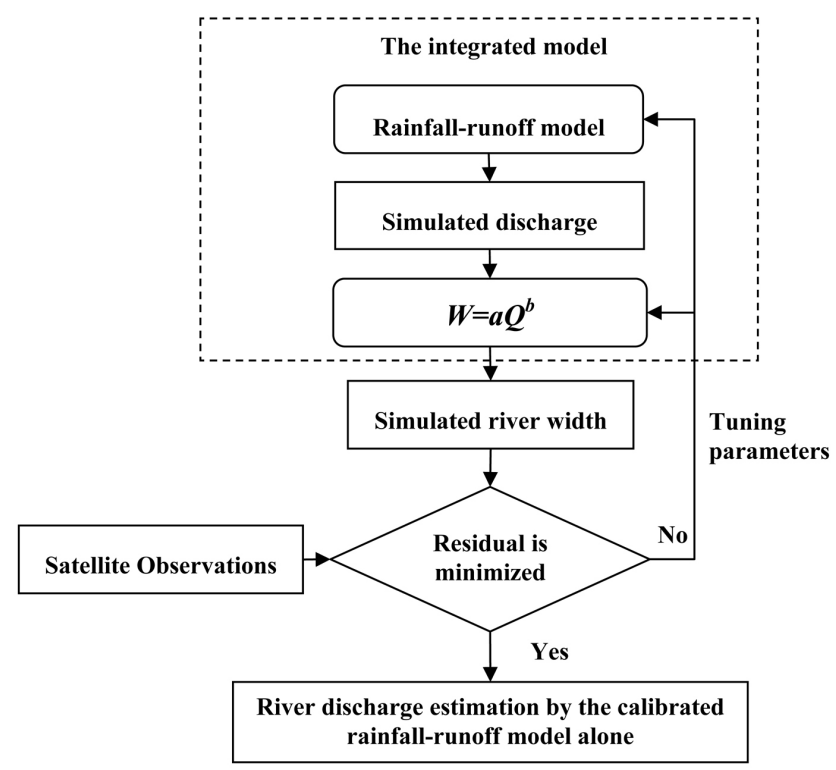

Fig. 1. Flowchart of the proposed framework for river discharge estimation.

discharge data and consequently facilitates the application in ungauged basins. Through this process of matching model simulation to satellite observations, the values of $a$ and $b$ are also identified as the rainfall-runoff modelling parameters, without referring to any information derived from ground measurement at the cross-section. The identified parameters are considered to reflect the runoff generation process and the "river width generation" process at the basin outlet appropriately. Finally, the calibrated rainfall-runoff model alone is utilized for river discharge estimation. The schematic of the methodology is illustrated in Fig. 1.

\subsection{Source of uncertainties under the calibration scheme}

Without the estimation of reliability, the proposed calibration scheme can not be applied with confidence. For hydrological modelling, prediction uncertainty comes from four types of sources: randomness of nature, error in data, parameter uncertainty and model structure. In the subsequent paragraphs, we focus on the statements of the additional uncertainties introduced by shifting calibration objective.

1. Uncertainties associated with at-a-station hydraulic geometry relation. The power relation is a simplification of the relation between discharge and river width, which can only approximate the hydraulic condition for in-bank flow at river segments that is not influenced by a strong backwater effect. The hydraulic relation between discharge and river width may change during the rising and falling limb of a flood wave. This phenomenon of hysteresis can not be explained by empirical relations like hydraulic geometry. Under the proposed method, the relation is assumed to be stable 
during the calibration period. However, the exponent and coefficient of the power function may vary over time in real situation, due to the changes in the cross-sectional shape. Another issue is that we implicitly assume that a parameter set that can make a good simulation of river width can also perform well for river discharge estimation. It is somehow doubtful, because the parameter adjustment is not based on discharge information.

2. Uncertainties associated with satellite observations of river width. The precision of river width measurement from space depends on the spatial resolution of satellite images (varies from $0.61 \mathrm{~m}$ for QuickBird data to $250 \mathrm{~m}$ for MODIS data), which leads to the fact that the measurement error is not negligible. Unlike using continuous river discharge data, utilization of intermittent satellite measurements mean that the parameter adjustment is only based on the information at the simulation time steps that observations are available. And the model behaviours in the time steps between observations (usually weeks to months long) are not regulated by the calibration.

\subsection{The GLUE framework}

The GLUE is a Bayesian analysis based Monte Carlo method for model calibration and uncertainty analysis (see Beven and Binley, 1992; Freer et al., 1996 for details). This framework is utilized in this study to make a quantitive analysis of uncertainty in the modelling process and derive some insights into the effectiveness of the proposed method. Due to limitations in model structure, data and calibration scheme, a common phenomenon in rainfall-runoff modelling is that a lot of quite different parameter sets can make equivalently accurate simulations (equifinality). GLUE gives up the thought that only one optimal parameter set exists, instead, it divides all parameter sets into two groups: behavioural ones and unbehavioural ones, based on the likelihood measure which quantifies the degree of belief of a parameter set being a good simulator. All of the behavioural sets are used for making simulation. The distribution of the likelihood value for behavioural sets is treated as a probabilistic weighting function for the predicted variables (Beven and Binley, 1992). According to this, a cumulative distribution of the model predictions is formulated and the uncertainty quantiles are computed. Under GLUE, some subjective choices are made explicitly, which are expected to be reasonable for the modelling work. The implementation of GLUE in this study is as follows:

1. Generate random samples from parameter space. A large number of parameter sets need to be generated for Monte Carlo simulations based on prior parameter distributions. In this study, the uniform distribution with lower and upper bounds are assumed to present the priori distributions of parameters.

2. Calculate the likelihood values for parameter sets and select behavioural ones. The likelihood measure quantifies the difference between simulation and observations. It should be assigned as zero for all parameter sets that can not reproduce the observations and should increase monotonically as the performance rises. The reciprocal of root mean square error (RMSE) is used and computed as follows:

$$
L_{y}[\boldsymbol{\theta} \mid Y]=\frac{1}{\sqrt{\frac{1}{n} \sum\left(Y_{i}-Z_{i}\right)^{2}}}
$$

where $L_{y}[\boldsymbol{\theta} \mid Y]$ is the value of likelihood measure for parameter set $\boldsymbol{\theta}$ conditioned on observations $Y, Y_{i}$ is the number $i$ satellite observation of river width, $Z_{i}$ is model simulated value at the time step that the number $i$ observation was made from space, and $n$ is the total number of satellite observations. The threshold for rejecting parameter sets as nonbehavioural ones is another subjective choice that needs to be specified. For the proposed calibration strategy, it depends on the resolution of satellite images, river size and degree of river width variation at basin outlet.

3. Calculate posterior likelihood distribution for behavioural parameter sets. Conditioned on the satellite observations, the likelihood is updated based on the Bayes' rule in the form:

$$
L_{p}[\boldsymbol{\theta} \mid Y]=C L_{y}[\theta \mid Y] L_{o}[\theta]
$$

where $L_{o}[\boldsymbol{\theta}]$ is the prior likelihood weight for the parameter set $\boldsymbol{\theta}$, which is the same for all behavioural sets in this study, $L_{y}[\boldsymbol{\theta} \mid Y]$ is the likelihood value calculated in step two, $L_{p}[\boldsymbol{\theta} \mid Y]$ is the posterior likelihood weight conditioned on observations $Y$, and $C$ is a scaling constant that makes the sum of $L_{p}[\boldsymbol{\theta} \mid Y]$ for all behavioural sets equal to unity.

4. Calculate uncertainty quantiles. The cumulative distribution of the predictions weighted by the likelihood is calculated as follows:

$P_{t}\left(Z_{t}<z\right)=\sum_{i=1}^{m} L_{p}\left[\boldsymbol{\theta}_{i} \mid Z_{t, i}<z\right]$

where $P_{t}\left(Z_{t}<z\right)$ is the cumulative probability of the value of predicted variable $Z$ less than an arbitrary value $z$ at time step $t, L_{p}\left[\boldsymbol{\theta}_{i}\right]$ is the posterior likelihood weight of parameter set $\boldsymbol{\theta}_{i}$, for which the prediction at time step $t\left(Z_{t, i}\right)$ is less than $z, m$ is the total number of the parameter sets satisfying the condition of $Z_{t, i}<z$. From this cumulative probability distribution, a lower $5 \%$ and upper $95 \%$ quantiles is obtained at every time step. These two quantiles for all simulation steps constitute the simulation limits, which characterise the uncertainty associated with the parameterization of the model conditioned on the model structure, input and calibration data, the parameter sets being used, and the subjective choices made in GLUE (e.g., the selection of likelihood measure and rejection threshold value). If the $90 \%$ simulation intervals are large enough to cover most of the observations, it means the parameter variability alone can account for the total output uncertainty (Blasone et al., 2008). However, 


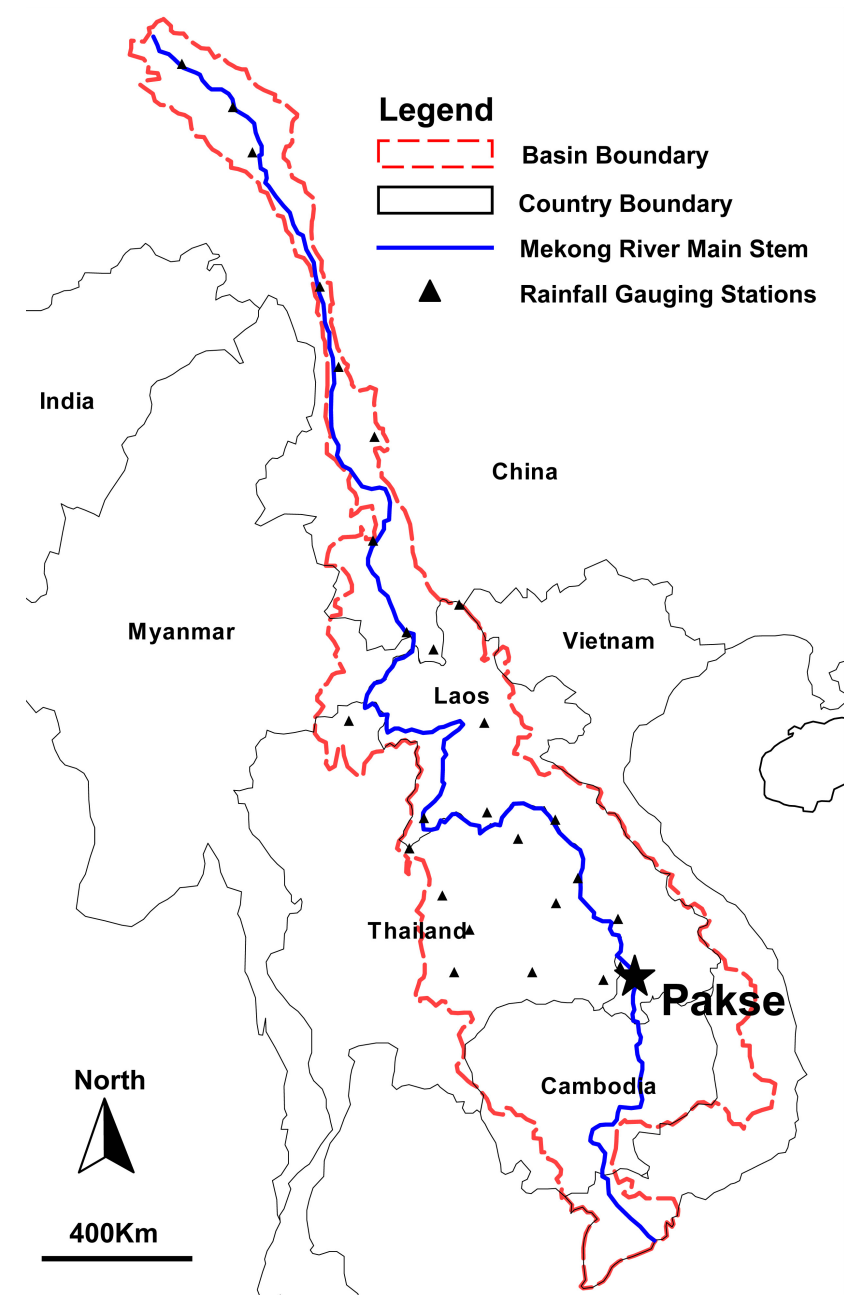

Fig. 2. Location of Pakse in the Mekong Basin and rainfall gauging stations.

many GLUE applications show that the prediction limits can not encompass the observations at the percentage equalling to the specified certainty level (e.g., the above defined $90 \%$ prediction limits) (Beven, 2006; Montanari, 2005) due to the uncertainties in the modelling process.

As illustrated in Fig. 1, the direct output of the integrated model is river width at basin outlet. The uncertainty limits of river width are expected to bracket most of river widths observations. At the same time, these limits should be narrow to guarantee predictive capability. Not referring to any information about discharge, the likelihood value is computed merely based on the performance of river width simulation. To make the discharge estimation, we assume that a parameter set can make good river width simulation and can also make equally good river discharge estimation. Then the posterior likelihood distribution obtained in step three is also treated as a probabilistic weighting function for river discharge. For the same period as calibration, the values of rainfall-runoff parameters in each behavioural parameter set are applied to the

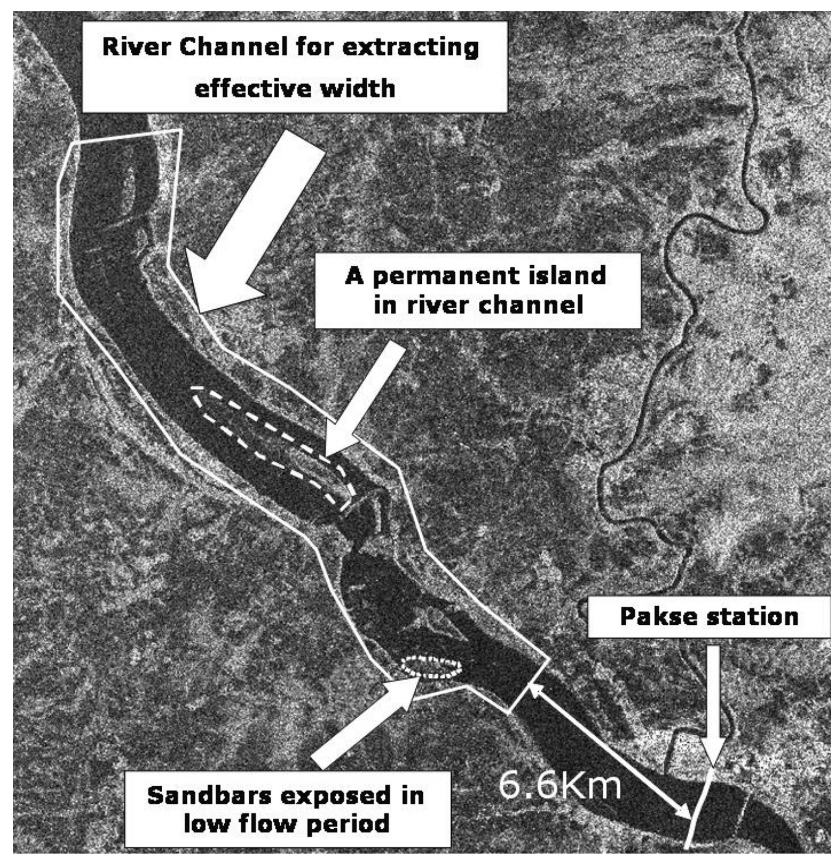

Fig. 3. The selected reach at Pakse for measuring river width from JERS-1 SAR images and examples of the area elements being measured.

rainfall-runoff model alone to make river discharge simulation. Subsequently, in the similar way as river width, uncertainty limits of river discharge are drawn, which define the uncertainty in the process of river discharge simulation.

\section{Application to Mekong River at Pakse}

\subsection{Description of study area}

The Mekong River is the 12th longest river in the world, with a drainage area of $795000 \mathrm{~km}^{2}$. It originates from the Tibetan Plateau and flows through Yunnan Province in China, Myanmar, Laos, Thailand, Cambodia and Vietnam, as shown in Fig. 2. Climate varies from cold in the upstream region to tropical climate in the downstream region. The annual average rainfall is around $1570 \mathrm{~mm}$. River discharge estimation was carried out for the Pakse gauging station, which is located in the main stem of the Mekong River, southwest Laos. The upstream area of Pakse $\left(545000 \mathrm{~km}^{2}\right.$, according to MRC, 2003) is treated as our target area for rainfall-runoff modelling.

\subsection{Extraction of river width from satellite imagery}

River widths at Pakse region were extracted from 16 scenes of JERS-1 SAR images (Level 2.1) captured during 19951998 , with a processed spatial resolution of $12.5 \mathrm{~m}$. JERS-1 was launched in February 1992 and terminated in October 1998 by Japan. Active microwave emitted by the SAR is 
Table 1. Parameter descriptions and ranges of random sampling.

\begin{tabular}{llll}
\hline Model & Name & Description & Range \\
& $C_{\max }$ & Maximum storage capacity & $1-500$ \\
& $B_{\exp }$ & Degree of spatial variability of the soil moisture capacity & $0-2$ \\
HYMOD & $\alpha$ & Factor distributing the flow between slow and quick release reservoirs & $0-1$ \\
& $K s$ & Residence time of the slow release reservoir & $0.001-0.5$ \\
& $K q$ & Residence time of the quick release reservoirs & $0.5-1.2$ \\
At-a-station Hydraulic geometry & $a$ & Coefficient of the power function & $1000-2000$ \\
& $b$ & Exponent of the power function & $0.005-0.1$
\end{tabular}

specularly reflected by smooth open water bodies. Backscatter values from river water surface are relatively consistent (Smith, et al., 1995), which facilitates water area classification. To reduce measurement error and localized variability, average river width (mentioned as "effective width" by Smith, et al., 1996) over a selected reach at Pakse was extracted. The spatial extent of the reach is shown in Fig. 3. The channel length is roughly 11 times of bankfull width at Pakse gauging station, which conforms to the suggestions of Bjerklie et al. (2005). For each image, the average width is calculated as:

$W_{e}=\frac{a_{w}}{l}=\frac{a_{a}-a_{i}-a_{s}}{l}$

$W_{e}$ is effective width, $a_{w}$ is water surface area within the reach, $l$ is reach length, $a_{a}$ is the total area within edge of water surface that contacts with river bank, $a_{i}$ is the area of permanent islands, and $a_{s}$ is the area of sandbars. The area components in Eq. (7) were delineated through visual interpretation as demonstrated in Fig. 3. In Fig. 4, the average river widths derived from space are plotted against corresponding daily river discharge data at Pakse station. The best fitted curve in the form of power function is $W=1221.3 Q^{0.0341}$. And a strong correlation $\left(R^{2}=0.92\right)$ exists between the two variables. The uncertainty bounds of the relation obtained from regression shown in Fig. 4 were defined by a simple method: moving the relation obtained from regression upwards by one standard derivation $(26.35 \mathrm{~m})$ of the difference between the satellite observations and values of river width computed from the best fitted curve using corresponding observed discharge as input, the upper boundary was obtained. Similarly, the lower boundary is the best fitted curve minus one standard deviation. The low exponent value $(0.0341)$ of the power relation, which is common in large rivers systems (Latrubesse, 2008), suggests that the increase in river width is not proportionate to the increase in the discharge: Ratio of discharge variation (maximum minus minimum) to minimum observed discharge in Fig. 4 is 19.4; but this ratio for river width observations from space is 0.1 . Moreover, detected river width variation (maximum minus minimum) is only nearly 13 times of spatial resolution of JERS-1 SAR images $(12.5 \mathrm{~m})$.

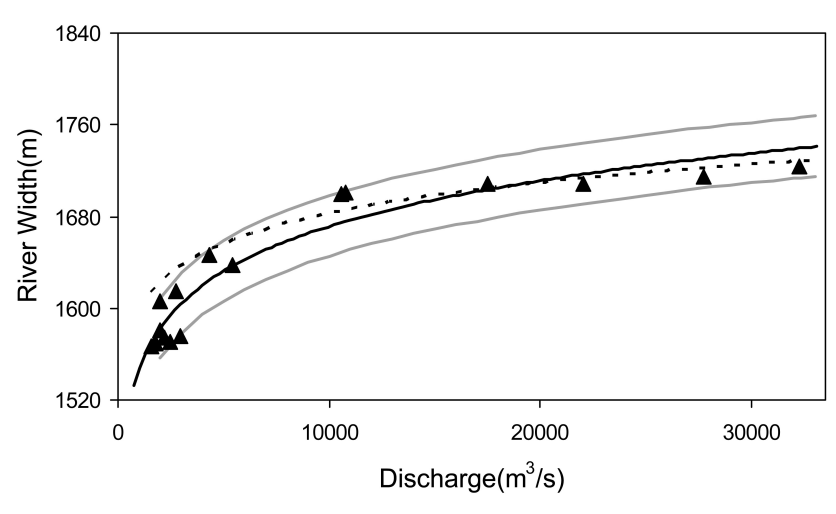

A Plots of observations Uncertainty bounds from regression Relation from regression _ - Best relation from calibration

Fig. 4. Plots of effective width derived from JERS-1 SAR images versus river discharge measured at Pakse gauging station, the relation obtained from regression with uncertainty bounds, and best relation obtained from calibration based on river width.

\subsection{Rainfall-runoff model and GLUE setup}

The HYdrological MODel (HYMOD) was used in this demonstrative case study. It was originally developed by Boyle (2001) and has been adopted in studies about hydrological model parameter estimation and uncertainty analysis (e.g., Moradkhani, et al., 2005; Schaefli and Gupta, 2007). Originating from the probability-distributed principle proposed by Moore (1985), HYMOD is a daily step rainfall excess model based on a nonlinear water storage capacity distribution function. The routing system includes a sequence of three quick-flow tanks which describe surface flow, in parallel to a slow-flow tank corresponding to groundwater. The model structure is depicted in Fig. 5 and parameters are listed in Table 1. The original HYMOD uses basin averaged rainfall and potential evapotranspiration as input, which cannot describe spatial heterogeneity adequately, due to the huge drainage area $\left(545000 \mathrm{~km}^{2}\right)$. It was revised to account for spatial variation in rainfall and evapotranspiration: The study area was divided into eight subbasins. HYMOD was applied to each subbasin, keeping the values of 


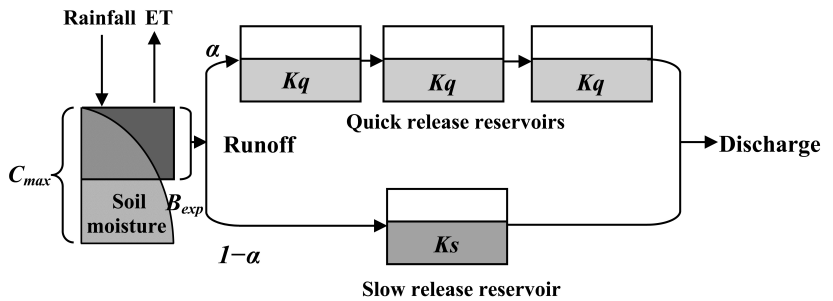

Fig. 5. Conceptual description of the HYdrological MODel (HYMOD).

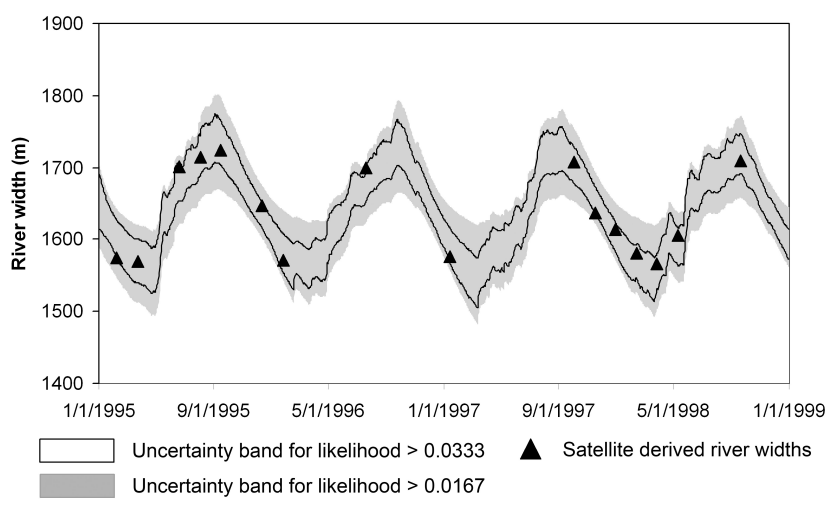

Fig. 6. Uncertainty bands for river width simulations made from parameter sets with associated likelihood values higher than 0.0167 and 0.0333 .

the three runoff generation parameters $\left(C_{\max }, B_{\exp }\right.$ and $\left.\alpha\right)$ same among the subbasins. The two routing parameters $(K q$ and $K s$ ) were treated as spatially varied ones, using the distance between each subbasin and Pakse as a scaling factor. At each time step, the amount of river discharge at Pakse is the sum of the water that comes from each subbasin, and reaching Pakse at that specific time step. The daily rainfall data from 26 stations for the period of 1995-1998, and Ahn and Tateishi monthly potential evapotranspiration (Ahn and Tateishi, 1994) were used as input. Observed river discharge data at Pakse station are also available for validation.

A total of seven parameters, five from HYMOD and the other two from the power relation between discharge and river width at Pakse (see Table 1) are calibrated under GLUE scheme. For calibration, 50000 parameter sets were generated using Latin-Hypercube sampling algorithm, based on uniform distribution and specified ranges of model parameters as shown in Table 1. According to Eq. (4), the likelihood value for each parameter set was computed, as a quantification of the difference between the river widths observed from space and river width estimates made by the integrated model, which was translated into the degree of goodness for each parameter set.

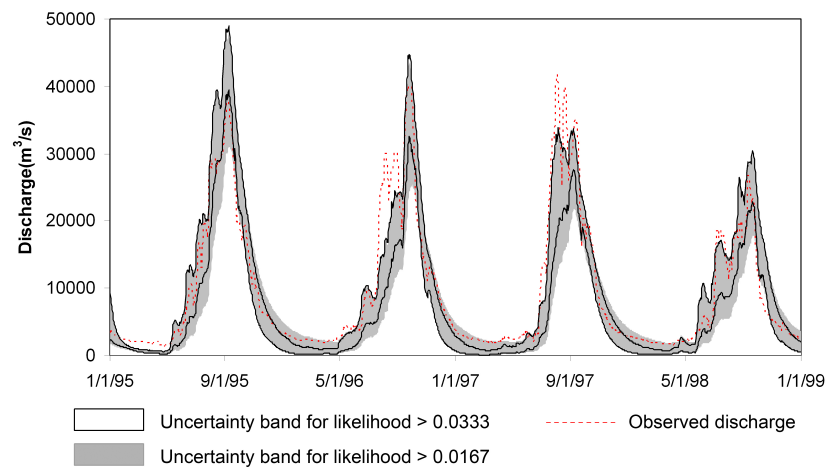

Fig. 7. Uncertainty bands for river discharge simulations made from parameter sets with associated likelihood values higher than 0.0167 and 0.0333 .

\section{Results and discussion}

\subsection{River width simulation}

The input-state-output behaviour of the model was examined. The selection of a proper criterion for rejecting parameter sets as nonbehavioural ones is a direct way of arriving at the balance between narrow simulation intervals and encompassing most of observations, after model structure, data and likelihood measure being decided. At first, we arbitrarily chose a low value for the likelihood measure (0.0167, corresponding RMSE: $60 \mathrm{~m}$ ) as rejection criterion. Out of 50000 generated samples, 1090 sets were kept as behavioural ones. The resulting uncertainty intervals are demonstrated in Fig. 6 . All of the 16 river width observations derived from space are embraced. To further reduce simulation uncertainty, a stricter criterion $(0.0333$, corresponding RMSE: $30 \mathrm{~m}$ ) was applied to draw simulation intervals. This time, only 151 sets reach this threshold. The observations are still encompassed by the simulation intervals. Meanwhile, the uncertainty is significantly reduced as shown in Fig. 6. This value is a more proper criterion, because the uncertainty seems to be minimized (locations of some observations are very close to the uncertainty boundary). The matching between river width estimates and satellite observations suggests the model input-state-output behaviour is reliable, which is one precondition for making a trustworthy river discharge estimation.

\subsection{River discharge estimation}

The rainfall-runoff model parameter values in each behavioural set were applied to HYMOD alone to simulate river discharge. Fortunately, in situ gauged discharge data at Pakse are available for inspecting the performance of river discharge simulation. Figure 7 depicts the uncertainty intervals for the two selected rejection thresholds, respectively. The $90 \%$ uncertainty intervals are close to observed 


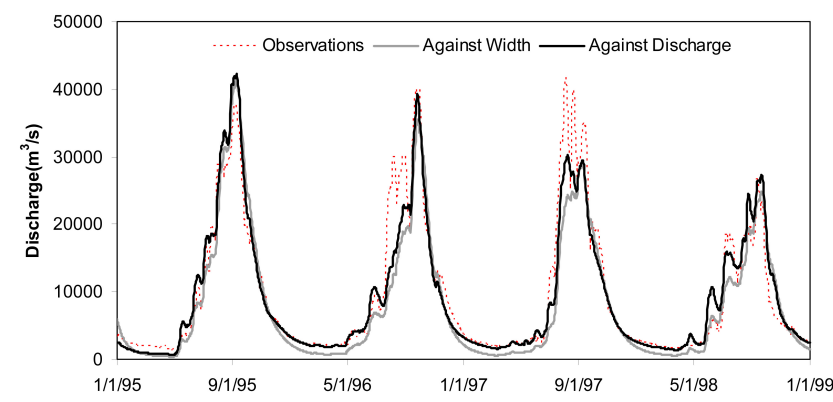

Fig. 8. Discharge time series at Pakse from observations, mean simulation of behavioural parameter sets by calibration against satellite observations of river width, and best simulation by calibration against observed discharge data.

daily discharge at Pakse. And timing of variation in river discharge is well reproduced. The percentage of observations within simulation intervals is $39.8 \%$ and $70.3 \%$ for threshold 0.0333 and 0.0167 , respectively, which are comparable with other hydrological modelling studies using GLUE (Montanari, 2005; Jia, 2008). Nevertheless, even all of river widths are within the simulation intervals, some of the river discharge observations are out of the uncertainty limits of discharge estimation. The inaccuracy of river discharge simulation results from the errors of the rainfall-runoff model itself and the shift of calibration objective. These two issues are examined below.

Calibration based on observed discharge data of 19951998 was carried out under GLUE, using the Nash-Sutcliffe efficiency of discharge as likelihood, and the same 50000 parameter sets being randomly generated and the same input forcing data. In Fig. 8, the simulated discharge by the parameter set that maximizes the value of Nash-Sutcliffe efficiency $\left(Q_{q}\right)$ are shown together with the mean simulated discharge of behavioural parameter sets obtained from calibration based on river width $\left(Q_{w}\right)$, and observed discharge at Pakse gauging station. $Q_{q}$ stands for the best capability of the rainfall-runoff model itself for reproducing the discharge at Pakse. The temporal variation patterns of $Q_{q}$ and $Q_{w}$ are similar, as shown in Fig. 8. For example, both simulations can not reproduce the flood peak in 1997 sufficiently in a similar way, which could be explained by the imperfect description of spatial variation in rainfall during the flood period. This indicates that the uncertainty associated with the rainfall-runoff model itself still exists for calibration based on river width.

The difference between the two simulations in Fig. 8 is a sign of the uncertainty introduced by shifting calibration objective. Under the proposed calibration scheme, an implicit assumption is made: a parameter set that makes good river width simulations can also produce equally good river discharge estimations. Only when this extrapolation of model performance from river width to discharge is valid, can the method be reliable. For each parameter set that the

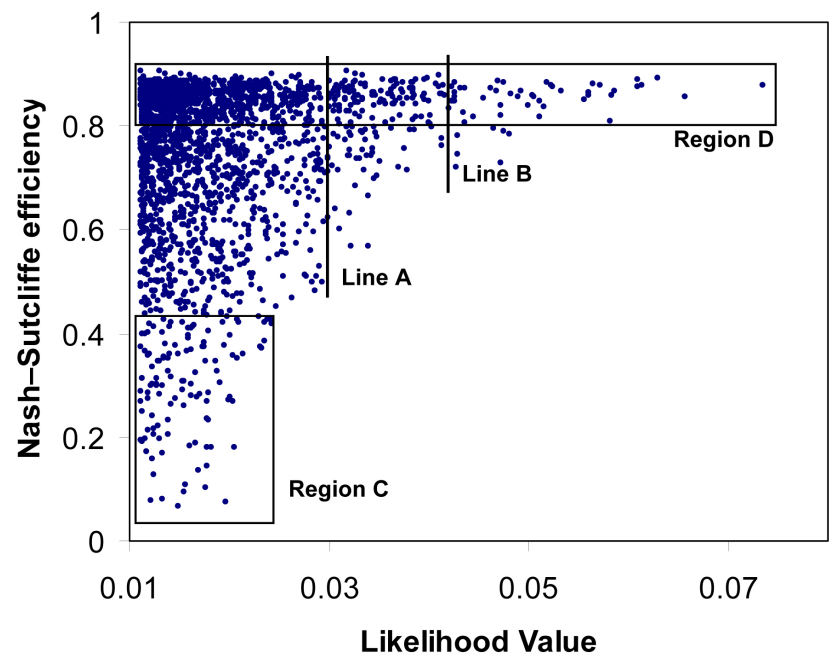

Fig. 9. Likelihood versus Nash-Sutcliffe efficiency of simulated discharge for parameter sets with associated likelihood values higher than 0.0167 .

likelihood value is higher than 0.0167 (RMSE $<60 \mathrm{~m}$ ), the Nash-Sutcliffe efficiency of simulated discharge was computed and plotted against the likelihood value, as shown in Fig. 9. It can be seen that the capability in reproducing river discharge varies among the plausible parameter sets that performs equally well in river width simulation (e.g., the plots crossed by Line A). However, as the likelihood value increases, this variation decreases among the parameter sets with same likelihood value, and the average performance increases (e.g., the plots on Line B are more converged than the ones on Line A and average Nash-Sutcliffe efficiency is higher). The above-mentioned characteristics indicate that a positive correlation exits, which somehow validates the assumption.

The distribution of the scatter plots also demonstrates limitations in using river width as calibration data. In Fig. 9, for plots in Region C, performance in discharge estimation is poor. This can partially be explained by the fact that judgments made by GLUE are only based on whether the likelihood value is good or not. But this issue is not a major concern, because the contributions of the sets in Region C to discharge estimation are limited, due to their relatively low likelihood value. The plots in Region D are more worth noting. They stand for the parameters sets that can make good discharge simulations and span the whole range of behavioural likelihood value. Many good parameter sets in this region indicate river width observations from space do work well as a surrogate of river discharge and also indicate the equifinality in rainfall-runoff modelling. The plots with low likelihood values in this region will have low weight in discharge estimations, due to their relatively poorer performance in river width simulation. This may cause some minor details about hydrograph being lost. But major variation in river discharge 

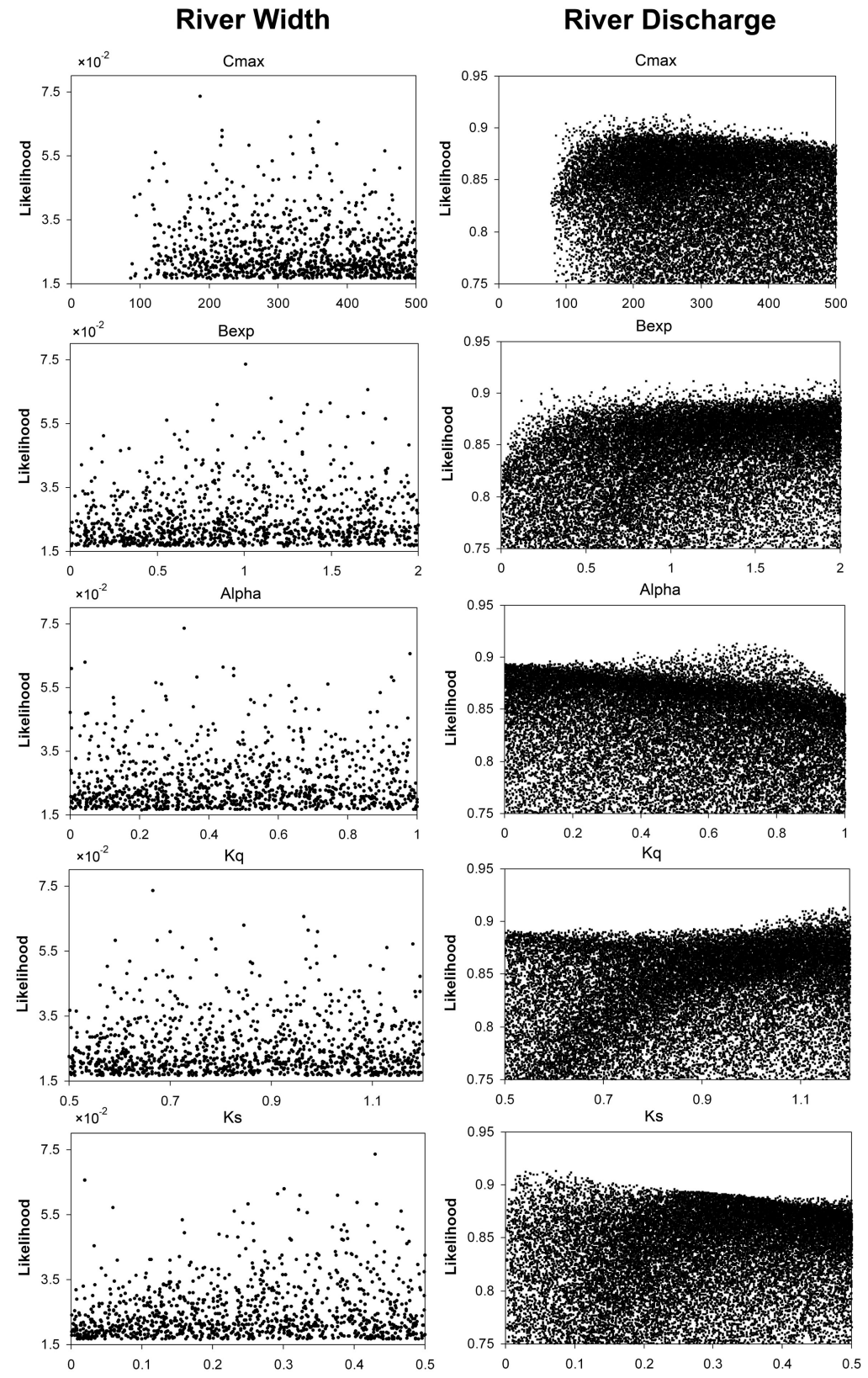

Fig. 10. Plots of likelihood value versus parameter values of the HYMOD for calibration against river width and river discharge, respectively.

can still be reproduced, because many sets with high likelihood values also exist in this region.

\subsection{Posterior parameter distributions}

Confidence in the proposed method also relies on the consistency between parameter estimates and reality of the basin. In this context, inspecting posterior parameter distributions conditioned on calibration data may give us some insights into model reliability (Winsemius, et al., 2006). For the behavioural parameter sets obtained from calibration based on river width (RMSE $<60 \mathrm{~m}$ ) and river discharge (NashSutcliffe efficiency $>0.75$ ), their likelihood values versus parameter values of the HYMOD are plotted in Fig. 10, respectively. Compared with calibration against discharge, the number of behavioural parameter sets is much lower for calibration based on river width, which partially implies that this calibration has stronger constraints on parameter space, due to increased complexity of model structure. The values of the parameter $C_{\max }$ identified from both calibrations are roughly the same (100 to 500), as shown in Fig. 10. This consistency 

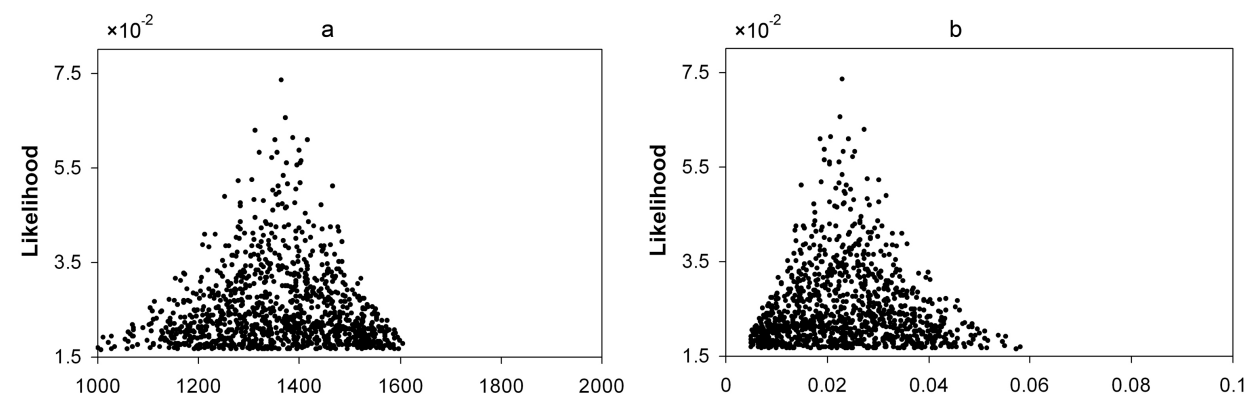

Fig. 11. Plots of likelihood value versus parameter values of the at-a-station hydraulic geometry relation.

could be considered as a sign for the effectiveness of the proposed method. However, for both calibrations, identified parameter values of the other four parameters are almost spread across the whole prior range.

In contrast, the two parameters of at-a-station hydraulic geometry relation (i.e., $a$ and $b$ in Eq. (2)) are strongly constrained by calibration, as shown in Fig. 11. This indicates that these two parameters are sensitive and they do not compensate for rainfall-runoff model parameters' effect. The values of $a$ and $b$ are determined by geometry and hydraulic condition of the cross-section (Ferguson, 1986; Dingman, 2007). They are usually derived through regression analysis based on values of discharge and river width observations. The posterior distributions of $a$ and $b$ are in single peak shape, which is consistent with the fact that a strong correlation between river width and discharge exists at Pakse. The parameter values that maximize likelihood measure are 1363.1 and 0.0230 , respectively, which are close to the best fitted curve ( $a=1221.3, b=0.0341)$ as demonstrated in Fig. 4. These facts raise the confidence that the relation between river width and discharge at Pakse region is properly reflected by posterior distributions of $a$ and $b$.

\subsection{Implications for application to ungauged basins}

Judging from the above three aspects, satellite observation of river width is a competent surrogate of observed discharge for the calibration of rainfall-runoff model. Admittedly, general insights for real applications to ungauged basins are limited from one single case study. However, some implications still can be obtained for future applications.

In spite of the fact that the river width variation at Pakse is only tenfold satellite resolution, the application was successful. It indicates that the proposed method could even be applicable to river segments with low width exponent value in at-a-station hydraulic geometry relation (less than 0.1 ), for which river width variation is low and consequently detecting this variation from space takes on highest difficulty. Besides a strong correlation between river discharge and width exists, which depends on the hydraulic process at basin outlet, another requirement for a successful application is that river width variation is detectable from space. The detectability is related to the sensor's resolution. Nowadays, satellite image products with decimeter level resolution (e.g., QuickBird) are available. As pointed out by $\mathrm{Xu}$ et al. (2004), besides large rivers, these very high resolution images make river width variation of medium size, even small size rivers detectable from space. Judging from the views of the crosssection type and river size, a broad applicability of the proposed method is promised.

Another distinct difference from calibration using river discharge is that only intermittent observations are used for parameter identification. In the case study, robust parameter sets were identified from the information provided by only 16 discontinuous observations during the 4 year period. This density of observations is in line with Perrin et al. (2007). Their results shows that using only 10 random selected values from 39-year long continuous daily discharge data is still possible to derive reasonable parameter estimates. This low requirement in satellite observation amount may come from the fact that the hydrograph variation at Pakse is regular and smooth, as depicted in Fig. 7, and satellite observations for both dry and wet conditions are included in calibration data. For such a hydrograph, only several observations per year may capture the essence of river discharge variation. Indeed, the information provided by the satellite observations should be enough to identify the parameters being calibrated. Montanari et al. (2009) have illustrated the situation that the calibration of a coupled hydrologic-hydraulic model based on satellite observations failed to identify model parameters, which was explained by the fact that the amount of remotely sensed information was not sufficient. To reproduce the hydrograph with high irregularity and variability, satellite observations with higher observation frequency are required. For basins without discharge gauging, temporal distribution in rainfall data may provide some clues to infer river discharge variability (Smakhtin and Masse, 2000).

The likelihood value for each parameter set defines the difference between river width observations and the simulation. Ultimately, it is treated as the degree of confidence in making good river discharge estimation. Results from this case study indicate that this extrapolation is effective, but not perfect: 
although the uncertainty quantiles can cover all river width measurements, the simulation intervals of river discharge can not encompass all observations. Through trial-and-error, a proper rejection threshold may be found to bracket most width observations with relatively narrow uncertainty intervals, just like the threshold 0.333 in the case study. However, a moderate threshold may be desired to cover more river discharge, as the threshold 0.167. There is no question that this will increase uncertainty in discharge estimation. But the uncertainty associated with the selection of rejection threshold could be examined under GLUE. It is also worth noting that the utilization of moderate threshold does not guarantee $100 \%$ coverage of river discharge, because it can not overcome the inherent error of the rainfall-runoff model itself.

To further explore the applicability, a question needs to be addressed: what kind of ungauged basins are suitable for the proposed calibration scheme? First, river discharge gauging is totally unavailable, or observed hydrological data are not accessible. Second, the input and forcing data for the selected rainfall-runoff model are available. Third, the at-astation hydraulic geometry is proper to approximate the relation between discharge and river width at the basin outlet, which requires that the reach should be alluvial and selfformed. Finally, the variation of the river width at basin outlet can be detected from remote sensing.

\section{Conclusions and recommendation}

In this study, a new calibration scheme for rainfall-runoff models was illustrated, aiming at improving river discharge estimation in ungauged basins. Based on at-a-station hydraulic geometry relation, simulated discharge by rainfallrunoff model is converted into river width at basin outlet. Through this integration, the calibration objective is shifted into minimizing the difference between river widths observed from space and simulated widths by tuning parameters of rainfall-runoff model and at-a-station hydraulic geometry relation simultaneously. The GLUE procedure was adopted to calibrate the integrated model and define the uncertainty associated with prediction. Under the proposed calibration scheme, the need for observed discharge is eliminated. At the same time, the difficulty of determining absolute discharge time series from satellite observations alone is also overcome. The full scope of this new calibration scheme was explored through the case study at Pakse in the Mekong Basin: The uncertainty intervals can cover all of the river width observations from space. The $90 \%$ uncertainty intervals for discharge are close to observed daily discharge at Pakse and satisfactorily reproduce the variation in the timing of discharge. From the plots of the likelihood value versus the Nash-Sutcliffe efficiency of simulated discharge, the positive correlation between model performance in river width simulation and performance in river discharge estimation is found. And the limitation of this assumption about the correlation shows minor impact on river discharge estimation. The posterior distributions of two at-a-station hydraulic geometry parameters can reflect the hydraulic condition at Pakse reasonably. It can be concluded that this calibration scheme would have wide applicability for reproducing river discharge time series on the daily scale in ungauged basins.

Under the GLUE scheme, data assimilation is easy to carry out. It is recommended in exploring the possibilities of updating likelihood distribution by assimilating each satellite observation of river width subsequently into the likelihood value for each parameter set through the Bayes' rule. In this study, the relation between discharge and river width at basin outlet is assumed to be constant. However, the relation maybe varies temporally, due to human activities, vegetation, erosion and deposition. Data assimilation would be a meaningful approach to reflect temporal variation in at-a-station hydraulic geometry relation and consequently have the potential to further improve the performance of river discharge estimation.

Acknowledgements. The authors sincerely acknowledge Ministry of Education, Culture, Sports, Science and Technology of Japan Grand-in-aid Scientific Research (No.21560537, PI: Hiroshi Ishidaira, University of Yamanashi) and Global Center of Excellence (GCOE) Program, Evolution of Research and Education on Integrated River Basin Management in Asian Region, University of Yamanashi for supporting this study.

Edited by: W. Wagner

\section{References}

Ahn, C.-H. and Tateishi R.: Development of a global 30-minute grid potential evapotranspiration data set, Journal of the Japan Society of Photogrammetry and Remote Sensing, 33(2), 12-21, 1994.

Alsdorf, D. E., Rodríguez, E., and Lettenmaier, D. P.: Measuring surface water from space, Rev. Geophys., 45, RG2002, doi:10.1029/2006RG000197, 2007.

Bastola, S., Ishidaira, H., and Takeuchi, K.: Regionalisation of hydrological model parameters under parameter uncertainty: A case study involving TOPMODEL and basins across the globe, J. Hydrol., 357(3-4), 188-206, 2008.

Beven, K. and Binley, A.: The future of distributed models: Model calibration and uncertainty prediction, Hydrol. Process., 6(3), 279-298, 1992.

Beven, K.: A manifesto for the equifinality thesis, J. Hydrol., 320(1-2), 18-36, 2006.

Birkett, C. M.: Contribution of the TOPEX NASA radar altimetry to the global monitoring of large rivers and wetlands, Water Resour. Res., 34(5), 1223-1239, 1998.

Bjerklie, D. M., Moller, D., Smith, L. C., and Dingman, S. L.: Estimating discharge in rivers using remotely sensed hydraulic information, J. Hydrol., 309, 191-209, 2005.

Bjerklie, D. M.: Estimating the bankfull velocity and discharge for rivers using remotely sensed river morphology information, J. Hydrol., 341, 144-155, 2007. 
Blasone, R.-S., Madsen, H., and Rosbjerg, D.: Uncertainty assessment of integrated distributed hydrological models using GLUE with Markov chain Monte Carlo sampling, J. Hydrol., 353, 1832, 2008.

Boyle, D. P.: Multicriteria calibration of hydrological models, Ph.D. Thesis, University of Arizona, USA, 2000.

Coe, M. T. and Birkett, C. M.: Calculation of river discharge and prediction of lake height from satellite radar altimetry: Example for Lake Chad basin, Water Resour. Res. 40(10), W102051, doi: 10.1029/2003WR002543, 2004.

Dingman, S.L.: Analytical derivation of at-a-station hydraulic geometry relations, J. Hydrol., 344, 17-27, 2007.

Ferguson, R. I.: Hydraulics and hydraulic geometry, Prog. Phys. Geogr., 10, 1-31, 1986.

Freer, J., Beven, K., and Ambroise, B.: Bayesian estimation of uncertainty in runoff prediction and the value of data : an application of the GLUE approach, Water Resour. Res., 32(7), 20612173, 1996.

Gupta, H. V., Beven, K., and Wagener, T.: Model calibration and uncertainty analysis, in: Encyclopedia of Hydrological Sciences, edited by: Anderson, M. G., John Wiley \&Sons, Ltd., USA, 2015-2032, 2005.

Jet Propulsion Laboratory: Surface Water and Ocean Topography Mission Science Requirements Document (Initial Release), California Institute of Technology, USA, http://swot.jpl.nasa.gov/ science/, 2009.

Jia, Y. and Culver, T. B.: Uncertainty analysis for watershed modelling using generalized likelihood uncertainty estimation with multiple calibration measures, J. Water Resour. Plan. Manage.ASCE, 134(2), 97-106, 2008.

Kouraev, A. V., Zakharova, E. A., Samain, O., Mognard, N. M., and Cazenave, A.: Ob's river discharge from TOPEX/Poseidon satellite altimetry (1992-2002), Remote Sens. Environ., 93, 238245, 2004.

Latrubesse, E. M.: Patterns of anabranching channels: The ultimate end-member adjustment of mega rivers, Geomorphology, 101(12), 130-145, 2008.

Leopold, L. B. and Maddock Jr., T.: The hydraulic geometry of stream channels and some physiographic implications, U.S. Geological Survey Professional Paper 252, U.S. Government Printing Office, 1953.

Montanari, A: Large sample behaviours of the generalized likelihood uncertainty estimation (GLUE) in assessing the uncertainty of rainfall-runoff simulations, Water Resour. Res., 41(8), doi:10.1029/2004WR003826, 2005.

Montanari, M., Hostache, R., Matgen, P., Schumann, G., Pfister, L., and Hoffmann, L.: Calibration and sequential updating of a coupled hydrologic-hydraulic model using remote sensingderived water stages, Hydrol. Earth Syst. Sci., 13, 367-380, doi:10.5194/hess-13-367-2009, 2009.

Moore, R. J.: The probability-distributed principle and runoff production at point and basin scales, Hydrol. Sci. J., 30(2), 273-297, 1985.

Moradkhani, H., Sorooshian S., Gupta, H. V., and Houser P. R.: Dual state-parameter estimation of hydrological models using ensemble Kalman filter, Adv. Water Resour., 28(2), 135-147, 2005.
MRC (Mekong River Commission): State of the basin report, MRC, Phnom Penh, ISSN: 1728-3248, 2003.

Perrin, C., Oudin, L., Andreassian, V., Rojas-Serna, C., Michel, C., and Mathevet, T.: Impact of limited streamflow data on the efficiency and the parameters of rainfall-runoff models, Hydrol. Sci. J., 52(1), 131-151, 2007.

Schaefli, B. and Gupta, H. V.: Do Nash value have value? Hydrol. Process., 21(15), 2075-2080, 2007.

Sivapalan, M., Takeuchi, K., Franks, S. W., Gupta, V. K., Karambiri, H., Lakshmi, V., Liang, X., McDonnell, J. J., Mendiondo, E. M., O'Connell, P. E., Oki, T., Pomeroy, J. W., Schertzer, D., Unlenbrook, S., and Zehe, E.: IAHS decade on predictions in ungauged basins(PUB), 2003-2012: shaping an exciting future for the hydrological sciences, Hydrol. Sci. J., 48(6), 857-880, 2003.

Smakhtin, V. Y. and Masse, B.: Continuous daily hydrograph simulation using duration curves of a precipitation index, Hydrol. Process., 14(6), 1083-1100, 2000.

Smith, L. C., Isacks, B. L., Forster, R. R., Bloom, A. L., and Preuss, I.: Estimation of discharge from braided glacial rivers using ERS 1 synthetic aperture radar: First results, Water Resour. Res., 31(5), 1325-1329, 1995.

Smith, L. C., Isacks B. L., Bloom, A. L., and Murray, A. B.: Estimation of discharge from braid rivers using synthetic aperture radar imagery: Potential application to ungauged basins, Water Resour. Res., 32(7), 2021-2034, 1996.

Smith, L. C. and Pavelsky T. M.: Estimation of river discharge, propagation speed, and hydraulic geometry from space, Lena River, Siberia, Water Resour. Res., 44, W0327, doi:10.1029/2007WR006133, 2008.

Schumann, G., Bates, P. D., Horritt, M. S., Matgen, P., and Pappenberger, F.: Progress in integration of remote sensing derived flood extent and stage data and hydraulic models, Rev. Geophys., 47, RG4001, doi:10.1029/2008RG000274, 2009.

Vörösmarty, C. J., Askew, A., Barry, R., Birkett, C., Döll, P., Grabs, W., Hall, A., Jenne, R., Kitaev, L., Landwehr, J., Keeler, M., Leavesley, G., Schaake, J., Strzepek, K., Sundarvel, S. S., Takeuchi, K., and Webster, F.: Global water data: A newly endangered species, AGU EOS Trans., 82(5), 54, 56, 58, 2001.

Wagner, W., Verhoest, N. E. C., Ludwig, R., and Tedesco, M.: Editorial "Remote sensing in hydrological sciences", Hydrol. Earth Syst. Sci., 13, 813-817, doi:10.5194/hess-13-813-2009, 2009.

Winsemius, H. C., Savenije, H. H. G., Gerrits, A. M. J., Zapreeva, E. A., and Klees, R.: Comparison of two model approaches in the Zambezi river basin with regard to model reliability and identifiability, Hydrol. Earth Syst. Sci., 10, 339-352, doi:10.5194/hess10-339-2006, 2006.

$\mathrm{Xu}, \mathrm{K}$. , Zhang, J., Watanabe, M., and Sun, C.: Estimating river discharge from very high-resolution satellite data: a case study in the Yangtze River, China, Hydrol. Process., 18, 1927-1939, 2004.

Zhang, J., Xu, K., Watanabe, M., Yang, Y., and Chen, X.: Estimation of river discharge from non-trapezoidal open channel using QuickBird-2 satellite imagery, Hydrol. Sci. J., 49(2), 247-260, 2004. 